\title{
STATISTICAL MODELLING OF THE SERVICE LIFE PREDICTION OF PAINTED SURFACES
}

\author{
C. CHAI a , Jorge De BRITO ${ }^{a}$, Pedro Lima GASPAR ${ }^{b}$, Ana SILVA ${ }^{a, *}$ \\ a Department of Civil Engineering, Architecture and Georesources, IST-Technical University of Lisbon, \\ Av. Rovisco Pais, 1049-001, Lisbon, Portugal \\ ${ }^{b}$ Faculty of Architecture, Technical University of Lisbon, Lisbon, Portugal
}

Received 27 June 2013; accepted 25 April 2014

\begin{abstract}
Service life prediction assumes a primary role as it allows a more rational use of construction elements. This constitutes a useful tool in the definition of preventive maintenance plans providing an increase in performance. The main objective of this research is the development of a statistical methodology for the service life prediction of external painted surfaces. This research is based on field data collected via a survey of the state of deterioration of in-service buildings. The degradation is defined by a number of factors that together contribute to the deterioration of painted surfaces thus ending their service life. In this study a mathematical model was defined using a multiple linear regression analysis and this enables the coating's deterioration over time to be expressed as a function of various degradation factors. 220 painted coatings were inspected in 160 buildings of varying construction types. Analytical tools were devised to monitor the performance of paint coatings on walls and estimate their service life. This study contributes to the automation of the maintenance of painted facades, allowing a more rational management of the maintenance of buildings, converted into economic and performance gains.
\end{abstract}

KEYWORDS: Service life prediction; Exterior painted surfaces; Degradation

\section{INTRODUCTION}

Façades are the building's most visible element and are therefore intimately linked to the quality of the urban environment (Flores-Colen, de Brito 2010). The incidence of anomalies in exterior coatings affects not only the appearance of the building. According to a study from the Building Research Establishment (BRE), these anomalies may lead to a decrease of about $50 \%$ of a building's functional performance, which lessens its durability (BRE 1988). Consequently, anomalies mean that more investment is needed for repair and rehabilitation (Rodrigues et al. 2013).

Teo et al. (2005) found that the cost of maintaining façades accounts for a significant percentage of the cost of intervening in buildings. Tools are therefore necessary so that the time to take action can be predicted, thereby allowing a more rational assessment of the construction elements through the definition of maintenance plans, which leads to lower repair costs (Zhang, Gao 2012). This im-

\footnotetext{
* Corresponding author. E-mail: anasilva931@msn.com
}

plies at careful, detailed planning of maintenance needs, with control of the materials and economic resources needed during the life cycle of the built environment that allows it to be managed in the most economical way (Daniotti, Spagnolo 2007).

For this purpose, it is important to monitor the health of buildings' façades during their life cycle. In the past decades, there has been a growing concern about health monitoring of the buildings and its components (Jiang et al. 2007; Park et al. 2007). In fact, health monitoring, non-destructive evaluation and active control of buildings (Jiang, Adeli 2005) under in use conditions plays a key role in service life prediction. The service life prediction of the materials and components of the built heritage is very important to achieving the maximum longevity - making the investment more profitable - and to allowing their correct selection, use and maintenance (Masters, Brandt 1987; Anoop et al. 2012). This is the only way to ensure that the maintenance work over the life cycle is planned as a function of the real degradation mechanisms of the 
construction materials and components, bearing in mind the degradation factors and the corresponding expected service lives (Chai 2011).

A study performed by Long et al. (2001) shows that the building stock represents more than 50\% of the national wealth of the developed countries. Therefore, in order to maintain the value of these assets, both in technical and economic terms, it is paramount that the degradation of constructed assets and their elements are assessed (Silva et al. 2012). However, the building stock is often much deteriorated, with economic, cultural and environmental consequences. In a time when resources are scarce, investment in periodical maintenance of the Portuguese building stock has been found to be inadequate (Dias et al. 2013). Nowadays, studies are very important to obtain reliability data and to turn these data into useful information for decision-making (Meeker, Escobar 1998). This study focuses on the service life prediction of painted coatings, the most popular coating solution in Portugal (INE 2001). For this, a statistical analysis was performed on the factors that affect the durability of painted coatings on exterior walls, using multiple linear regression. The method proposed is based on data collected on the performance of construction elements in real in-service exposure conditions, through visual inspections and subsequent modelling of the data, in the context of the Lisbon building stock and based on a survey of the degradation state of 220 coatings. The service life prediction method proposed can be directed at the building park's management and maintenance market. The knowledge of the service life of painted surfaces allows property researchers and practitioners to more rationally and technically-informed manage real estate and the building stock. This study is a useful tool to property researchers and practitioners, providing information on when the maintenance actions on the facade should be taken, avoiding unnecessary costs (due to excessive maintenance actions or emergency repairs) and allowing a real estate maintenance strategy.

\section{QUANTIFICATION OF THE DEGRADATION OF EXTERNAL PAINTED COATINGS}

This study set out to statistically model the factors that influence the degradation of external painted coatings. To that end, in-service buildings were inspected under an extensive field work program with the objective of characterizing the performance of buildings in real in-use conditions. According to Gaspar (2009), this option is the one that best fits the scope of current buildings' management and maintenance operations since it accommodates the technical and budgetary resources generally available in design, supervision, technical management, maintenance and condominium administration offices and firms.

The field work included a visual survey of the state of repair of painted coatings. A statistical analysis was performed on the findings, which result from long-term exposure to in-service conditions. There was no exhaustive, detailed survey of every anomaly and only the degradation mechanisms were visually inspected, i.e. the anomalies that result from and can model the progress of the coatings' degradation, other than localized and random occurrences or that caused by accidental phenomena (e.g. graffiti), which are impossible to model.

As much additional data as possible is gathered before starting the field work in order to put each case study into perspective. This data consists mostly of location maps and views to scale (Fig. 1). These documents yield quantitative information on

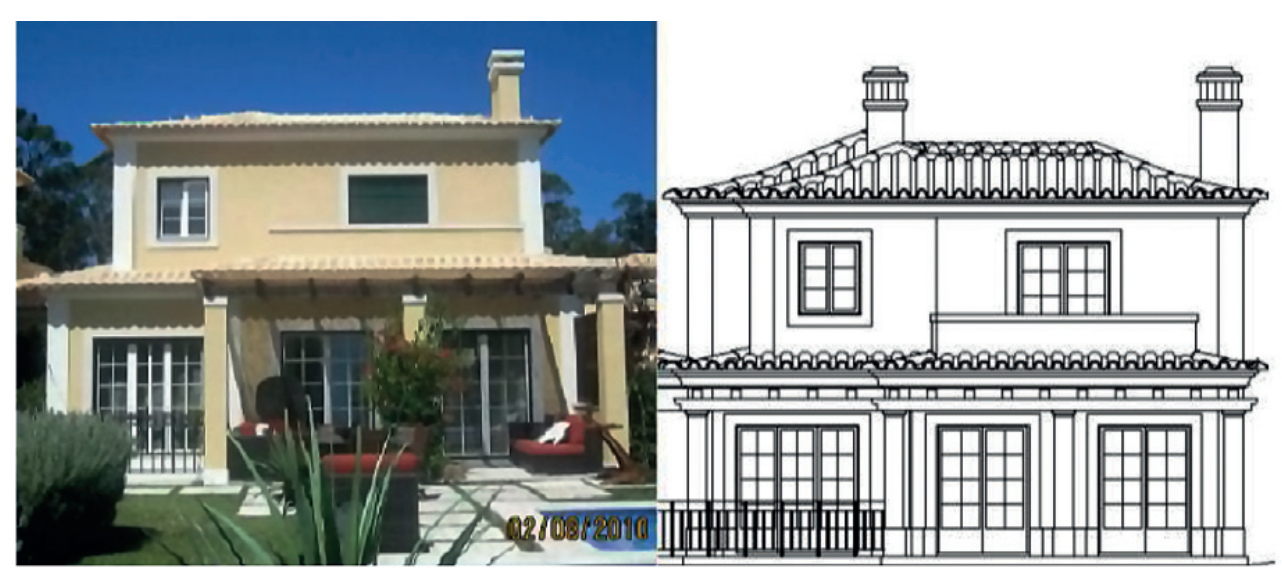

Fig. 1. Photo and view of a façade under analysis (from a CAD file) 
size-related aspects of the façades which facilitates the measurement of the opaque area and the area affected by anomalies, besides providing information on the number of floors and an estimate of the size of the buildings to be inspected.

In this study, compact and low-rise buildings of up to 4 floors and $14 \mathrm{~m}$ tall were preferred, in particular those whose façades were mostly straight, with no indentations, projections, additional volumes, corners or recesses. The goal was to make it easier to have an unhindered view of the upper part of the façade and to facilitate the visual examination of the degradation.

Data was collected on the parameters that have the most influence on the service life of the coatings, according to standard ISO 15686 (2000), namely: the materials' characteristics; the design factors; the execution factors; the environmental conditions, and maintenance. Being able to specify the degradation factors considered in this work presupposes that the method adopted is able to identify and quantify them. Therefore, and even though their importance in the performance of coatings has been reliably proved, execution factors were excluded because it was impossible to know, for example, the conditions under which the paint was applied, the type of workmanship or the application method. The materials' characteristics, the design factors, the environmental conditions and maintenance parameters were decomposed into variables (Table 1), identified during the field work for each case study. Each of these variables comprises façades with common characteristics, thus enabling the creation of a concise and useful database for the goal envisaged. Whenever possible, the method was kept simple to allow its use by non-specialized construction technicians (Gaspar 2009).

Table 1. Decomposition of the degradation factors into variables, which can be identified in field work

\begin{tabular}{l}
\hline Materials' characteristics \\
Type of product \\
Surface preparation \\
Paint colour \\
Paint finish \\
Design factors \\
Number of floors \\
Environmental and exposure conditions \\
Distance from pollutant sources \\
Exposure to humidity \\
Distance from the sea \\
Wind-rain action \\
Façade orientation \\
Maintenance \\
Age of the coating
\end{tabular}

Internationally, several service life prediction methods have been put forward in recent years (Flourentzou et al. 1999; Möller et al. 2004; Li et al. 2007; Choi, Seo 2009; Aktas, Bilec 2012; Garrido et al. 2012; Dias et al. 2013). The main methods to estimate the service life of constructed assets can be classified in deterministic, probabilistic and engineering (a symbiosis of the previous two) (Daniotti 2003; Lacasse, Sjöström 2004). Deterministic methods (e.g. the factor method, proposed in ISO 15686:2000) are based on an analysis of degradation mechanisms that affect the elements studied; these methods are subject to numerous criticisms, because they are unable to capture the random nature of the degradation phenomena. The probabilistic methods (e.g. Markov chains) are more complex and look at degradation as a stochastic process that evolves probabilistically over time.

The method proposed by Gaspar and de Brito (2005), Gaspar (2009), Shohet et al. (2002, 2003) and Shohet and Paciuk (2004) was chosen to determine the global degradation level of the façades analysed, as a function of the main categories. This method is based on a systematic visual appraisal of the degradation of a significant sample of façades of different ages. The appraisal involves surveying the anomalies and collecting quantitative and qualitative data on: size aspects of the façades; areas affected by each anomaly; degradation level associated with each anomaly; data on the degradation factors of each façade for subsequent analysis of their influence.

Gaspar and de Brito (2008, 2011) proposed a numerical index that expresses the global degradation of façade coatings through the ratio between the degraded area weighted as a function of its condition and a reference area, equivalent to the whole and having the maximum degradation level possible. This method, was initially validated for current renderings, established a framework method that could afterwards be adapted to other façade claddings such as ceramic tiling (Bordalo et al. 2011) and natural stone claddings (Silva et al. 2011a, b; 2012). The overall degradation of external painted surfaces is thus quantified using this numerical index, as seen in equation (1).

$$
S_{w}=\frac{\sum\left(A_{n} \times k_{n} \times k_{a, n}\right)}{A \times k},
$$

where: $S_{w}$ - degradation severity of the coating, expressed as a percentage; $k_{n}$ - multiplying factor of anomalies $\mathrm{n}$, as a function of their degradation level, within the range $K=\{0,1,2,3,4\}$; $k_{a, n}$ - weighting factor corresponding to the rela- 
tive weight of the anomaly detected $\left(k_{a, n} \in \mathrm{R}+\right)$; $k_{a, n}=1$ by default; $A_{n}$ - area of coating affected by an anomaly $\mathrm{n}$, in $\mathrm{m}^{2} ; A$ - façade area, in $\mathrm{m}^{2}$; $k$ - multiplying factor corresponding to the highest degradation level of a coating of area A.

The extent of the anomalies and their level of severity (rated 0-4) consist of data collected on site. Regarding the balance between anomalies, several scenarios were studied for the indicators $S_{w}$, based on a hierarchical relationship between the four groups of anomalies (stains/change in brightness and colour, cracking, chalking and loss of adherence). In each scenario, various relative weights were tested for these groups of anomalies and the results were analysed regarding their ability to translate the physical reality registered. Table 2 represents the weighting coefficients that achieved the best results by reducing the weighting of stains/colour changes anomalies and increasing the weighting of the loss of adherence.

\section{STATISTICAL MODELLING USING MULTIPLE LINEAR REGRESSION ANALYSIS}

The multiple regression analysis model is one of the statistical techniques most commonly used for investigating and modelling the relationship between a dependent variable (also called the endogenous or response) and one or more independent variables (predictors) (Wang, Gibson Jr. 2010; Mata 2011). When the regression analysis is used in prediction models, the main objective is to explain a given reality and try to anticipate the role of a dependent variable as a function of the independent variables.

This statistical technique has been successfully used to solve complex problems in many fields of science, including medicine (Honjyo et al. 2005), socio-economic analysis and politics (Alt, Lassen 2006), veterinary (Woods et al. 2003) to name but a few of various areas. This method also has been proven a powerful and efficient tool for use in solving civil engineering and construction problems (Wang, Elhag 2007; Mata 2011; Oral et al. 2012).

Table 2. Weighting coefficients

\begin{tabular}{lllll}
\hline Anomalies & $\begin{array}{l}\text { Stains } \backslash \\
\text { Colour } \\
\text { changes }\end{array}$ & $\begin{array}{l}\text { Crack- } \\
\text { ing }\end{array}$ & $\begin{array}{l}\text { Peeling and } \\
\text { blistering }\end{array}$ & $\begin{array}{l}\text { Chalk- } \\
\text { ing }\end{array}$ \\
\hline $\begin{array}{l}\text { Weighting } \\
\text { coefficient }\end{array}$ & 0.25 & 1.00 & 1.50 & 1.00 \\
\hline
\end{tabular}

In the literature, several prediction methods (Flourentzou et al. 1999; Shohet et al. 2002, Shohet, Paciuk 2004; Gaspar, de Brito 2008, 2011) were based on a simple regression analysis only. This type of analysis cannot take into account all the dimensions of the problem which it tries to solve. There are other mathematical and computational methods that have been successfully applied to the service life of building components. Markov chains have been used to predict the life cycle performance and the service life of building materials (Lounis et al. 1998; Zhang et al. 2005); this method takes into account the odds of transition from one level of degradation to another. Neural networks have been applied in the service life prediction of rendered facades (Silva et al. 2013) and exterior stone cladding (Silva et al. 2011b). Other methods, as logistic regression, first and second-order reliability methods, and numerical simulations can be also applied in service life prediction.

The application of multiple linear regressions as an auxiliary tool to support decision-making in the lifetime of a construction, e.g. decisions related to maintenance, is relatively recent (Silva et al. 2012, 2013). This statistical and computational tool is not new but it was never been applied in the service life prediction of painted surfaces.

Service life prediction is associated with many variables and is not an exact science (BSI 7543, 1992). An efficient methodology of service life prediction must be able to distinguish the significant variables from the many non-significant variables (Martin et al. 1996). The degradation of exterior painted coatings is influenced by various degradation factors that synergistically play a part in ending their service life. It is therefore useful to analyse the simultaneous action of the various parameters considered in order to determine the way each of them influences the severity of degradation. The goal of the multiple linear regression model proposed is to anticipate the behaviour of degradation severity (dependent variable) as a function of what is known about the various degradation factors (independent variables). This should identify the factors that contribute most to explaining the variability of the coatings' degradation and to establishing a ranking of these factors.

The multiple linear regression model is generally defined by equation (2) (Chou, Tsai 2003).

$$
y=b_{0}+b_{1} x_{1}+\ldots+b_{p} x_{p}+\varepsilon=b_{0}+\sum_{i=1}^{p} b_{i} x_{i}+\varepsilon,
$$

where: $y$ - dependent variable (estimated by the model); $x_{i}$ - independent variables $(i=1,2 . ., p) ; p-$ 
number of independent variables in the model; $b_{0}-$ constant of the model; $b_{i}$ - regression coefficient corresponding to independent variable $x_{i}(i=1$, $2 \ldots, p) ; \varepsilon$ - random errors of the model, which represent the difference between the values observed and predicted (or estimated) of the population.

After the model is built some basic assumptions must be verified. They can be divided into two steps: the analysis of the residuals and the analysis for multicollinearity. For more explanations see Hair et al. (2007) or Meeker and Escobar (1998).

\section{SELECTION AND BUILDING OF THE MODEL}

SPSS (Statistical Package for Social Science) was used in this work, as well as the Excel regression analysis data package. The step-by-step (Stepwise) method used to define the explanatory variables. In this method the basic regression assumptions are revised, and the variables that are not significant or explanatory of the dependent variable are excluded. According to Leung et al. (2001) the multicollinearity effects are also eliminated.

Chai (2011) performed an extensive study on the degradation factors of external painted coatings. The 220 cases analyzed did not provide unequivocal conclusions on some factors (which are excluded from this model), namely: surface preparation (due to the small number of case studies for which information is available); paint color, type of product and distance from pollutant sources (whose results were not consistent with what was expected in terms of common sense).

The first step in the construction of the model consists of quantifying the qualitative variables considered, i.e. exposure to humidity, distance from the sea, wind-rain action, façade orientation and paint finish. Each of these was decomposed into categories or qualitative values and had to be converted into numerical values to be taken as inputs of the model. There are various ways of doing this, the simplest being to adopt a linear (for three categories) or binary (for two categories) conversion scale.

Chai (2011) and Chai et al. (2014) analyzed the progression of degradation of painted surfaces by representing it graphically through degradation curves. This analysis enabled an estimate of the service life of the coatings to be obtained according to some of their characteristics; the estimated service life is obtained graphically by the intersection of the line that defines the maximum admissible degradation limit (in this case a severity limit of $20 \%$ was adopted) and the corresponding degradation curve. To define this limit, the degradation state of each case study was analyzed. It was found in this analysis that adopting a maximum level of degradation of $10 \%$ is too conservative to establish the end of the service life (at this level, the degradation of painted surfaces is still incipient, not justifying any maintenance actions). On the other hand, the maximum level of degradation of $40 \%$ seems to be too high, since the degradation state of the painted surfaces is too widespread, which leads to thinking that it is preferable to adopt a lower level. Therefore, it is suggested that $20 \%$ or $30 \%$ are the most adequate values to establish the end of the service life of the façades. In this study the maximum level of degradation chosen was $20 \%$, since it was found to be more adequate in the case studies analysed from a sensorial point of view. Once again it is stressed that this level is hard to define and that it must be analysed with caution since it depends mostly on the acceptance criteria of the building owners/promoters. To illustrate this concept, Figure 2 shows a case study at the end of its service life (severity around $20 \%$ ).

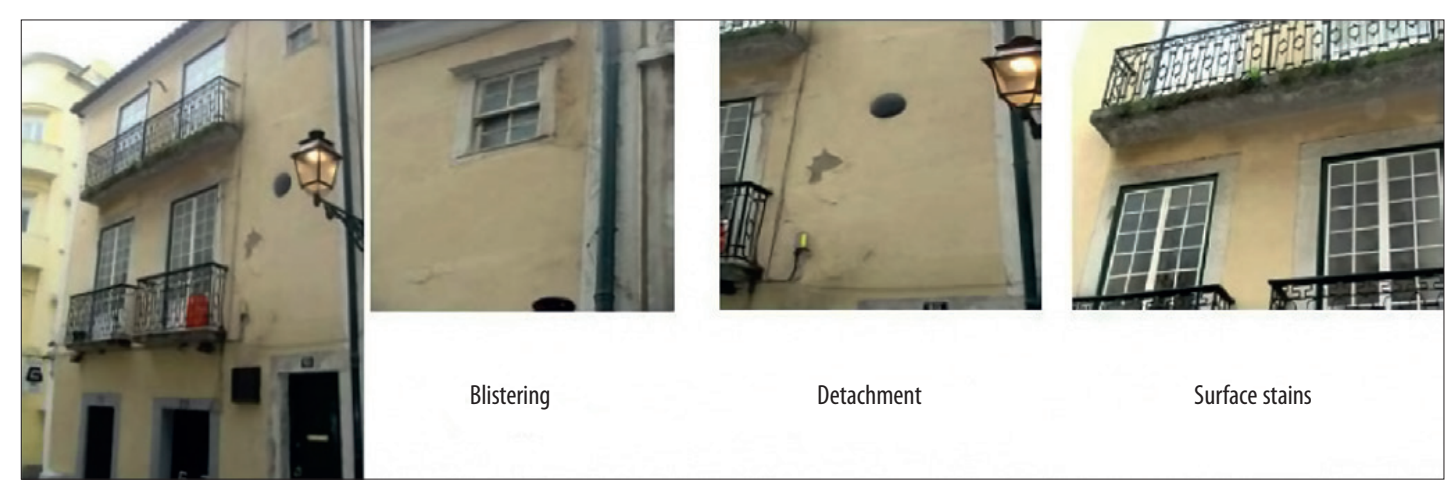

Fig. 2. Case study representative of the end of the service life of façade paintings (degradation severity around 20\%) 
The degradation limit which establishes the end of service life is a subjective concept and not generally easy to specify (Moser 2004), since new performance requirements are being demanded all the time, forcing constant investment to keep up with them and to delay the degradation trend affecting the cladding (Gaspar 2009). This limit is also referred to as the minimum accepted performance level and it is a relative concept that varies according to the time, place and even the funds available for maintenance and repair work. Iselin and Lemer (1993) reported that there are no rational criteria to guide the decision to intervene, but rather subjective and programmatic criteria. A study conducted by Aikivuori (1999) shows that in only $17 \%$ of cases the decision to intervene is made based on the deterioration of the building.

In our analysis each category was associated with a value that represents the ratio between the estimated service life as a function of each coating characteristic and the reference service life of 9.75 years (Chai 2011; Chai et al. 2014). The resulting values are presented in Table 3 .

\subsection{Interpretation of results}

Various models were tested, with constants equal to and different from zero, and it was concluded that the model that yields the best results takes $b_{0} \neq 0$. Only the model giving the best results, as defined by the Stepwise method, is presented.

Based in the multiple linear regression analysis performed, it is concluded that the degradation severity (dependent variable) depends on the age of the façades, the distance from the sea and façade orientation. This conclusion seems correct and has physical sense, in fact, a study conduct by Shohet and Paciuk (2006) shows that seashore environment and UV radiation (associated with façade orientation) are typical mechanisms of failure that lead to degradation of exterior claddings. The Pearson correlation coefficient $(\mathrm{R})$ obtained in this case as a value of 0.912 , indicating a strong correlation between the variables, and it can be stated that the correlation between the estimated and observed values is very high. The value of the adjusted determination coefficient $\mathrm{R}^{2}$ adjusted $=0.83$ indicates that $83 \%$ of the variability of the severity is explained by age, façade orientation and distance from the sea, while the other $17 \%$ is due to factors not included in the model. These results can be interpreted as a sign that the method can yield satisfactory results in terms of service life prediction and that the degradation factors considered in this analysis are relevant and consequently explanatory of the degradation of painted façades.

The results from the Anova table (part 1) make it possible to test the null hypothesis $\left(\mathrm{H}_{0}\right)$ through the $\mathrm{F}$ test, which represents the ratio between the variance explained by the model and the one not explained. The null hypothesis $\left(\mathrm{H}_{0}\right)$ assumes that none of the independent variables included in the model explains the variability of the dependent variable. In this analysis, where $p$ is an output of the ANOVA table, the value of this probability ( $F$ of significance) is compared with the significance level targeted. Given a 10\% significance level and

Table 3. Values adopted when converting qualitative variables into quantitative ones

\begin{tabular}{|c|c|c|c|c|c|c|}
\hline \multirow[t]{2}{*}{ Exposure to humidity*1 } & Qualitative scale & Current & & Unfavourable & & \\
\hline & Quantitative scale & 1.03 & & 0.95 & & \\
\hline \multirow[t]{2}{*}{ Distance from the sea } & Qualitative scale & Less than $1 \mathrm{~km}$ & Betweer & $\mathrm{n} 1$ and $5 \mathrm{~km}$ & More than & $5 \mathrm{~km}$ \\
\hline & Quantitative scale & 0.94 & 0.96 & & 1.03 & \\
\hline \multirow[t]{2}{*}{ Façade orientation } & Qualitative scale & North & South & East & & West \\
\hline & Quantitative scale & 1.05 & 0.93 & 1.04 & & 0.93 \\
\hline \multirow[t]{2}{*}{ Wind-rain action*2 } & Qualitative scale & Slight & Modera & & Severe & \\
\hline & Quantitative scale & 1.04 & 1.02 & & 0.96 & \\
\hline \multirow[t]{2}{*}{ Paint finish } & Qualitative scale & Rough & & Smooth & & \\
\hline & Quantitative scale & 1.01 & & 0.96 & & \\
\hline
\end{tabular}

*1 The criteria adopted in the quantification of the exposure to humidity concern the urban context, the intensity of rain and the distance from the river: current, for facades located more than $1 \mathrm{~km}$ from the river; unfavourable, for facades located less than $1 \mathrm{~km}$ from the river.

$* 2$ The criteria adopted in the quantification of rain incidence concern the height of the building and the density of occupation of the soil in the area analyzed: light, for low-rise buildings (up to 2 storeys), in densely populated areas, protected from the trade winds by other buildings, adjacent hills or vegetation; moderate, for medium-high buildings, in currently populated urban areas, protected from the trade winds by other buildings, adjacent hills or vegetation; severe, for buildings more than 4-storeys high or in open country or crossroads. 
Table 4. ANOVA table of the multiple linear regression model (part 2: regression coefficients and individual analysis of the significance of each regression coefficient

\begin{tabular}{lllllll}
\hline & Coefficient $\left(\mathrm{b}_{\mathrm{i}}\right)$ & $\begin{array}{l}\text { Standard de- } \\
\text { viation }\left(\mathrm{S}\left(\mathrm{b}_{\mathrm{i}}\right)\right)\end{array}$ & Stat $t$ & P value & Lower 90.0\% & Upper 90.0\% \\
\hline Constant $\left(b_{0}\right)$ & 0.4734 & 0.1715 & 2.7602 & 0.0063 & 0.1901 & 0.7568 \\
Age $\left(x_{1}\right)$ & 0.0353 & 0.0011 & 31.171 & $6.802^{-82}$ & 0.0334 & 0.0372 \\
Distance from the sea $\left(x_{2}\right)$ & -0.2618 & 0.1438 & -1.8207 & 0.0700 & -0.4993 & -0.0243 \\
Façade orientation $\left(x_{3}\right)$ & -0.3175 & 0.0906 & -3.5028 & 0.0006 & -0.4672 & -0.1677 \\
\hline
\end{tabular}

since $p=4.10632^{-83}<\alpha=0.10, \mathrm{H}_{0}$ is rejected at the $10 \%$ level.

Moreover, since $\mathrm{p}$ is the probability that corresponds to the lowest significance level that leads to the rejection of $\mathrm{H}_{0}$, $(1-p)$ represents the confidence level. It can then be stated that for a confidence level of $\left(1-4.10632^{-83}\right) \times 100 \approx 100 \%$ at least one of the variables considered in the model is significant. It is thus concluded that the global model obtained is significant; however, this does not mean that all variables considered are explanatory. Therefore, it is now necessary to evaluate each of the parameters individually.

The individual importance of an independent variable $x_{i}$, included in a multiple linear regression model with $\mathrm{p}$ independent variables should be evaluated by a significance test of the corresponding parameter $b_{i}$. Table 4 shows the significance of each parameter and helps to understand the calculation of the equation of the multiple linear regression model. For a significance level of $10 \%$, it is concluded that all results belong to critical region where $p<\alpha$. Therefore, all coefficients are statistically significant and so all the variables analysed are explanatory of the dependent variable (degradation severity). This was expected since, under the Stepwise method, the variables that did not comply with this criterion were excluded from the model.

Furthermore, as with the $\mathrm{F}$ test, since $\mathrm{p}$ is the probability that corresponds to the lowest significance level that leads to the rejection of $\mathrm{H}_{0}$, $(1-$ p) represents the confidence level. It can then be stated that:

- with a confidence level of $\left(1-6.802 \times 10^{-82}\right) \times$ $100 \approx 100 \%$, the variable $x_{1}$ (age) is statistically significant;

- with a confidence level of $(1-0.0700) \times 100 \approx$ $93 \%$, the variable $x_{2}$ (distance from the sea) is statistically significant;

- with a confidence level of $(1-0.0006) \times 100 \approx$ $100 \%$, the variable $x_{3}$ (façade orientation) is statistically significant.
Therefore, it can be concluded that the degradation severity of painted surfaces depends on the three independent variables, ranked as follows: age, façade orientation and distance from the sea. Table 4 also presents estimates of the $90 \%$ confidence interval for each regression coefficient. The concept of confidence interval is used to estimate a regression coefficient for a sample collected randomly from a larger population. The confidence interval allows the uncertainty associated with each estimate to be expressed, thus indicating its precision. The amplitude of the confidence interval for each variable depends on the standard deviation values $\mathrm{S}\left(\mathrm{b}_{\mathrm{i}}\right)$; the greater these values the wider the interval or, in other words, the lower the accuracy of the estimate. Therefore, and as with the model's significance, it can be concluded that the accuracy of the estimate follows the ranking age, façade orientation and distance from the sea.

Table 4 presents the values expected for the regression coefficients, permitting expression of the built model (equations 3 and 4).

$$
\begin{aligned}
& y=0.4734+0.0353 x_{1}-0.2618 x_{2}-0.3175 x_{3}, \\
& S_{w}=0.4734+0.0353 \text { Age }-0.2618 \text { Sea }- \\
& 0.3175 \text { Orientation. }
\end{aligned}
$$

To apply the mathematical formula to estimate the degradation of painted surfaces as a function of the explanatory variables each variable must be replaced by its numerical value (the conversion from qualitative to quantitative variables is shown in Table 2).

The sign of each coefficient reflects the scale adopted: for variable "age" it is positive (the severity grows with age); for the "distance from the sea" and "façade orientation" variables it is negative, i.e. the higher their numerical value the lower the severity. The quantitative scale adopted in the definition of these parameters establishes that the less favourable the exposure conditions are the lower their numerical value (defined by the ratio between the estimated service life and 
the reference service life); therefore, the negative sign was to be expected.

\subsection{Validation of the assumptions of the model}

As mentioned, the results assume that the basic assumptions are verified and therefore they are only valid after the assumptions are actually proved true.

The residuals are analysed in 3 steps: verification of the normal distribution, analysis of the average and the variance, and study of the independence. A normal P-P plot is used to find whether the random variable "residuals" have a normal distribution, thus representing the expected probability, if the distribution were normal, as a function of the observed probability (Fig. 3). It shows that all the points in the graph lie around a line; it can thus be concluded that the residuals follow a normal distribution such that $e_{j} \sim N\left(\mu, \sigma^{2}\right)$.

In this analysis the average and the variance of the residuals are analysed through a graph of the residuals versus the value of the independent variable "age" (Fig. 4). Alternatively, the residuals could have been represented as a function of any other independent variable or the dependent variable "severity". Figure 4 shows that the expected value of the residuals is close to zero, i.e. $\mathrm{E}\left(\mathrm{e}_{\mathrm{j}}\right) \approx$ 0 . However, in terms of variance the width of the cloud of points is not completely uniform; after 15 years there are various points with a high residual compared with the remaining sample. This may have two causes. The first concerns the presence of atypical points, also called outliers, which are not representative of the sample. They can be detected through casewise diagnostics analysis, which

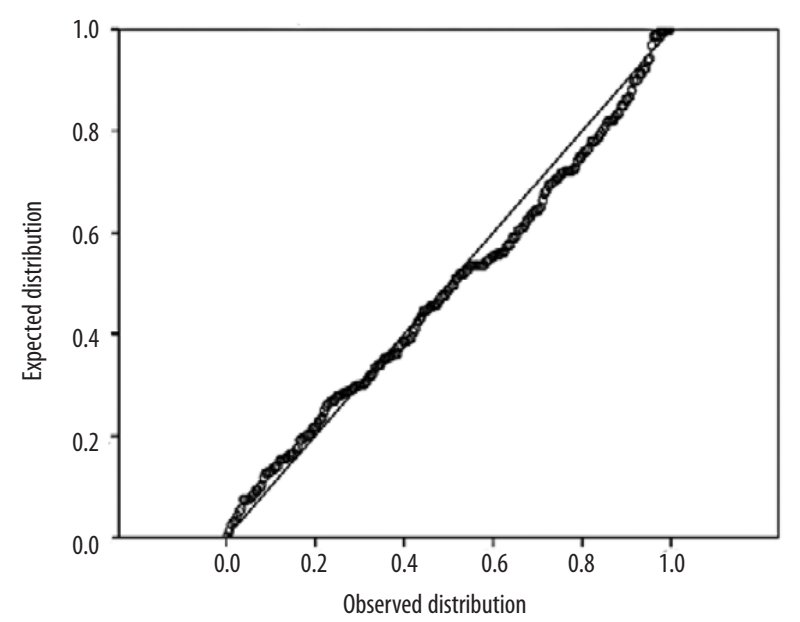

Fig. 3. Normal P-P Plot of the model

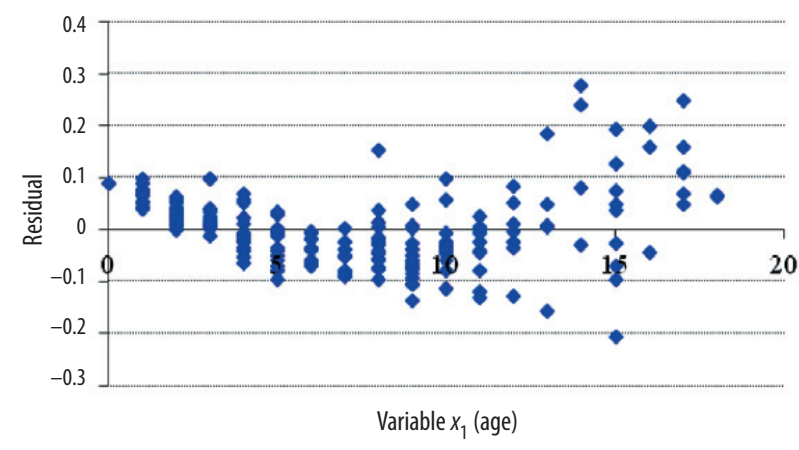

Fig. 4. Residuals versus dependent variable $x_{1}$ (age)

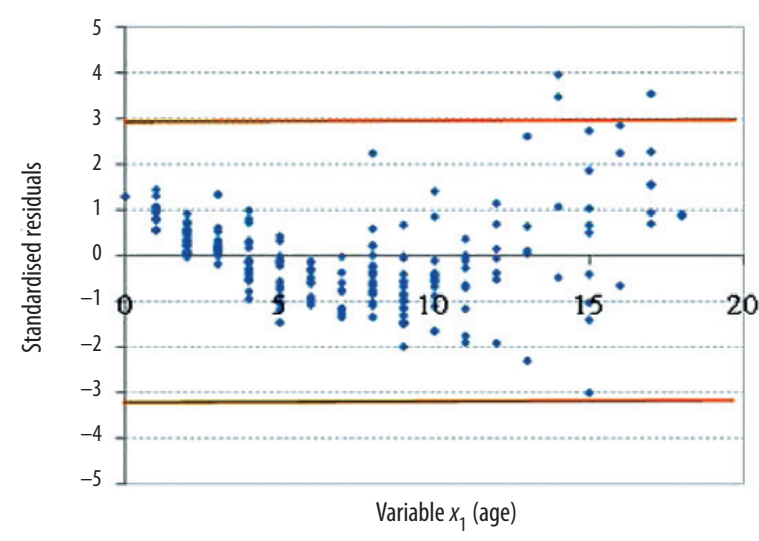

Fig. 5. Standardised residuals versus dependent variable $x_{1}$ (age)

holds that when the standardised residuals (ratio between the residuals and the standard deviation of the model) are higher than 3 it means that those observations are outliers. Figure 5 shows the distribution of the standardised residuals versus the independent variable "age". It shows that there are three examples whose standardised residuals' values are higher than 3.

Table 5 shows that these outliers relate to observations 4, 27 and 146 that correspond to case studies L004, L0025 and L116, respectively. A new model without these points can be analysed to compare its explanatory capacity with that of the model described so far.

The case studies mentioned have very high degradation levels $(>63 \%)$, and the model predicts lower severity values (estimated values). This may indicate that the model is better at predicting the severity of cases with low degradation. In fact, the model obtained by multiple linear regression conveys a constant rate of degradation as a function of age, façade orientation and distance from the sea. Since the numerical values that represent the façade orientation and the distance from the sea for each case do not vary over the service life, it was more or less expected that this model would give 
Table 5. Analysis of outliers (Casewise diagnostics)

\begin{tabular}{lllll}
\hline \multicolumn{2}{l}{ Casewise diagnostics } & & \\
\hline Observation & Standardised residuals & Observed value (severity) & Estimated value (severity) & Residual \\
\hline 4 & 3.513 & 0.7245 & 0.4759 & 0.2486 \\
27 & 3.924 & 0.6802 & 0.4026 & 0.2776 \\
146 & 3.448 & 0.6323 & 0.3883 & 0.2440 \\
\hline
\end{tabular}

Table 6. Durbin-Watson critical values for the proposed model

\begin{tabular}{|c|c|c|c|c|c|}
\hline d & $\begin{array}{l}{\left[0 ; d_{L}[=\right.} \\
{[0 ; 1.643[}\end{array}$ & $\begin{array}{l}{\left[\mathrm{d}_{\mathrm{L}} ; \mathrm{d}_{\mathrm{U}}[=\right.} \\
{[1.643 ; 1.704[}\end{array}$ & $\begin{array}{l}{\left[\mathrm{d}_{\mathrm{U}} ; 4-\mathrm{d}_{\mathrm{U}}=[1.704 ;\right.} \\
2.296[\end{array}$ & $\begin{array}{l}{\left[4-\mathrm{d}_{\mathrm{U}} ; 4-\mathrm{d}_{\mathrm{L}}[=\right.} \\
{[2.296 ; 2.357[}\end{array}$ & $\begin{array}{l}{\left[4-\mathrm{d}_{\mathrm{L}} ; 4[=\right.} \\
{[2.357 ; 4[}\end{array}$ \\
\hline Decision & $\begin{array}{l}\text { Reject } \mathrm{H}_{0} \\
\text { Dependence }\end{array}$ & Inconclusive & $\begin{array}{l}\text { Not reject } \mathrm{H}_{0} \\
\text { Independence }\end{array}$ & Inconclusive & $\begin{array}{l}\text { Reject } \mathrm{H}_{0} \\
\text { Dependence }\end{array}$ \\
\hline
\end{tabular}

Table 7. Matrix of correlations between variables of the proposed model

\begin{tabular}{lllll}
\hline Model & & Age & Façade orientation & Distance from the sea \\
\hline \multirow{2}{*}{ Correlations } & Age & 1.000 & -0.160 & -0.344 \\
& Façade orientation & -0.160 & 1.000 & 0.083 \\
& Distance from the sea & -0.344 & 0.083 & 1.000 \\
\hline
\end{tabular}

Table 8. VIF (variance inflation factor) values for each explanatory variable of the proposed model

\begin{tabular}{ll}
\hline Independent variable & VIF \\
\hline Age $\left(x_{1}\right)$ & 1.157 \\
Façade orientation $\left(x_{2}\right)$ & 1.027 \\
Distance from the sea $\left(x_{3}\right)$ & 1.135 \\
\hline
\end{tabular}

a constant degradation rate. However, degradation tends to accelerate during the course of service life, with synergetic phenomena between degradation mechanisms being one reason for this. The results may thus be interpreted as a sign that, from a given age onwards, degradation is better defined by nonlinear, possibly polynomial, curves to model a progressive increase in the degradation rate.

The second reason behind high residuals in some observations may be the absence from the model of one or more independent variables that in some combinations significantly influence the dependent variable, and so, too, the errors. If this were true, and given an apparent trend of the residuals to increase with age, it could mean that missing from the model is a variable whose action is initially slow (in the interval when residuals are small) but then tends to build up as time goes by (leading to higher residuals). This analysis requires the study of more degradation factors.

The graph does not reveal a well-defined pattern of the residuals, but there seems to be an intermediate situation between a uniform cloud and a pat- tern. Therefore, within the scope of this analysis, the result obtained is accepted as good.

The residuals' independence was ascertained through the Durbin-Watson statistic (Durbin, Watson 1971), leading to a d value of 1.795 . Using the tables established by Savin and White (1977), for $n=200$ case studies (maximum number of observations in the tables) and $k=3$ independent variables, a lower limit $d_{L}=1.643$ and an upper limit $d_{U}=1.704$ are obtained. The decision is based on the figures from Table 6 . Since $d \in\left[d_{U} ; 4-d_{U}[=\right.$ $\left[1.704 ; 2.296\left[, \mathrm{H}_{0}\right.\right.$ is not rejected, i.e. it can be concluded that the residuals are independent.

Meanwhile, multicollinearity is ascertained with the analysis of the matrix of bivariate correlations between variables (Table 7). Correlation values above 0.7 generally indicate multicollinearity problems between two variables. Table 8 indicates that there is no linear dependence between any of the model's independent variables.

The analysis of the VIF (variance inflation factor) values in Table 8 confirms there is no exact relationship between two or more independent variables $(\mathrm{VIF}<5)$.

\section{RESULTS DISCUSSION}

Six independent explanatory variables were analysed using this model: age, distance from the sea, exposure to humidity, façade orientation, windrain action and paint finish. The characteristics 
Table 9. Matrix of bivariate correlations between the degradation factors analysed

\begin{tabular}{lllllll}
\hline & Age & $\begin{array}{l}\text { Exposure to } \\
\text { humidity }\end{array}$ & $\begin{array}{l}\text { Wind-rain } \\
\text { action }\end{array}$ & $\begin{array}{l}\text { Distance from } \\
\text { the sea }\end{array}$ & Façade orientation & Paint finish \\
\hline Age & 1.000 & & & & & \\
Exposure to humidity & 0.361 & 1.000 & & & & \\
Wind-rain action & 0.250 & 0.088 & 1.000 & & \\
Distance from the sea & 0.336 & 0.946 & 0.053 & 1.000 & 1.000 & \\
Façade orientation & 0.140 & -0.017 & 0.101 & -0.031 & 1.000 \\
Paint finish & -0.161 & -0.066 & -0.001 & -0.133 & 0.080 & \\
\hline
\end{tabular}

were quantified for all the degradation factors, based on the ratio between the service life estimated for each factor and the reference service life for the complete sample. Only three variables were considered to explain the degradation: age, distance from the sea, exposure to humidity, and façade orientation. By themselves they explained $83 \%$ of the degradation identified in the sample.

Analysing the categories adopted for the parameters "exposure to humidity" and "distance from the sea", the criteria adopted are linked to some extent: most coatings with an unfavourable exposure to humidity (in the Cascais and Oeiras municipalities) are also less than $1 \mathrm{~km}$ from the sea or between $1 \mathrm{~km}$ and $5 \mathrm{~km}$ from it. Only some cases in the Amadora municipality have unfavourable exposure to humidity and are more than $5 \mathrm{~km}$ from the sea. The linear relationship between these two variables can be analysed in Table 9, which shows a correlation coefficient of 0.95 . This is why the variable "exposure to humidity" was excluded from the model.

The other two variables excluded from the model (wind-rain action and paint finishing) show no linear relationship with the other factors. Nor did they show enough statistical significance to be considered to explain the degradation (at a $10 \%$ significance level), although that does not mean they have no influence on degradation.

Having analyzed the global significance of the model and its independent variables, studied its explanatory capacity and verified the assumptions of the multiple linear regression, it is concluded that degradation severity can be explained by three independent variables: age, distance from the sea and façade orientation, using equation (4). It is now possible to calculate the estimated service life (ESL). For each case in the sample and a severity level of $20 \%$, it is given by equation (5), where age is now the dependent variable.

$$
E S L=\frac{(0.20-0.4734+0.2818 \text { Distance from the sea }+0.3175 \text { Façade orientation })}{0.0353} .
$$

Table 10. Summary of the statistical indicators for the reference service life, estimated using the proposed multiple linear regression model

\begin{tabular}{ll}
\hline Statistical indicator & $\begin{array}{l}\text { Value } \\
\text { (years) }\end{array}$ \\
\hline $\begin{array}{l}\text { Average of the reference service life } \\
\text { Maximum reference service life }\end{array}$ & 8.5 \\
Minimum reference service life & 7.6 \\
Range of reference service lives & 1.6 \\
$\begin{array}{l}\text { Standard deviation of } \\
\text { the reference service life }\end{array}$ & 0.54 \\
$\begin{array}{l}\text { Variance of the reference service life } \\
\text { 90\% confidence interval of the average of } \\
\text { the reference service life }\end{array}$ & 0.3 \\
\hline
\end{tabular}

Once the variables "distance from the sea" and "façade orientation" are converted to numbers (Table 3), it is possible to estimate the expected age for a degradation severity of $20 \%$. The reference service life provided by this multiple linear regression model is thus the average of all the ESL values of each observation, and a maximum value, a minimum value, a range and a standard deviation of the reference service life can also be determined, as seen in Table 10. The estimated reference service life ( 8.5 years) given by this model is lower than that (9.75 years) obtained by Chai (2011) and Chai et al. (2014) who used a simple nonlinear regression model. However the magnitude is consistent with the existing perception relative to the durability of painted coatings.

The value of reference service life obtained can be used to evaluate the economic and environmental performance of painted surfaces throughout their life cycle (acquisition, development, opera- 
tion, maintenance, repair deconstruction/demolition), allowing the comparison of different investment scenarios (Woodward 1997). These values also allow the optimization of inspection and maintenance plans and implementing a more rational management of the resources spent in constructions during their service life.

\section{CONCLUSIONS}

The model to estimate the service life of construction elements presented in this study is based on the visual appraisal of the anomalies, their quantification and the transposition of the results into the proposed model. The data collected and the combination of the information on the anomalies detected in in-service conditions were converted into numerical data - to be included in the degradation models - by defining an indicator that conveys the global degradation level of paint coatings.

In the individual analysis of the degradation factors, it was found that the most influential of those considered were exposure to humidity, windrain action, distance from the sea, façade orientation and paint finish. The simultaneous analysis of the degradation factors revealed that $83 \%$ of the degradation can be explained by three independent variables through a multiple linear model with a significance level of $10 \%$, ranked thus: age, façade orientation and distance from the sea. These data enable it to be said that, under circumstances similar to those of the sample analysed, the average service life of painted coatings is around 8.5 years. There are other relevant factors for durability, such as the thickness of the paint coat and the execution conditions, but these were not analysed due to the lack of available records or the difficulty of collecting data without resorting to laboratory analyses, which were beyond the scope of this work.

It should be noted that the definition of the maximum admissible level of degradation and the relationship between degradation severity and condition are both prone to some subjectivity and could therefore be adapted to other perspectives, and thus lead to different results. It was possible to estimate a reference service life based on the equation that mathematically defines the multiple linear regression model.

Finally, the approach proposed supplements studies on the performance of materials that use laboratory tests and accelerated ageing tests to assess their physical properties. The method proposed is based on the visual appraisal of the degradation and does not require resources other than those used by an inspector in the course of regular maintenance of the built heritage. It therefore costs little in time and money and is easy to implement. To this end, F. Tolman and A. Tolman (2003) state that in the construction sector, more specifically in the realm of buildings maintenance, it is important to develop simple tools that are relatively intuitive and quick to apply.

The method proposed in this study facilitates the automation of maintenance interventions. The mathematical formula obtained enables the estimation of the service life of painted facades according to the exposure conditions. Using this tool it is possible to understand how long the exterior facade will last, according to the use conditions. With this information, at the design phase, the stakeholders can define and predict the future costs spent in maintenance actions, as well as the materials used and the construction techniques applied in the execution of the exterior claddings. The automation of maintenance actions can reduce the consumption of natural resources, allowing a more rational management of the future management and monitoring of construction.

\section{ACKNOWLEDGEMENTS}

The authors gratefully acknowledge the support of the ICIST Research Institute, IST, Technical University of Lisbon and of the FCT (Foundation for Science and Technology).

\section{REFERENCES}

Aikivuori, A. 1999. Critical loss of performance - what fails before durability, in Proceedings of the 8th International Conference on Durability of Building Materials \& Components, 30 May - 3 June 1999, Vancouver, Canada, 1369-1376.

Aktas, C. B.; Bilec, M. M. 2012. Service life prediction of residential interior finishes for life cycle assessment, International Journal of Life Cycle Assessment 17: 362-371. http://dx.doi.org/10.1007/s11367-011-0367-6

Alt, J. E.; Lassen, D. D. 2006. Fiscal transparency, political parties, and debt in OECD countries, European Economic Review 50: 1403-1439. http://dx.doi. org/10.1016/j.euroecorev.2005.04.001

Anoop, M. B.; Raghuprasad, B. K.; Balaji Rao, K. 2012. A refined methodology for durability-based service life estimation of reinforced concrete structural elements considering fuzzy and random uncertainties, Computer-Aided Civil and Infrastructure Engineering 27(3): 170-186. http://dx.doi.org/10.1111/j.14678667.2011.00730.x

Bordalo, R.; de Brito, J.; Gaspar, P.; Silva, A. 2011. Service life prediction modelling of adhesive ceramic tiling systems, Building Research and Information 
39(1): 66-78. http://dx.doi.org/10.1080/09613218.2010 .532197

BRE 1988. Common defects in low-rise traditional housing, Digest 268, Building Research Establishment, Garston, UK.

BSI 7543:1992. Guide to durability of buildings and building elements, British Standards Institution, London, United Kingdom.

Chai, C. 2011. Service life prediction of painted surfaces in external walls, Master Dissertation in Civil Engineering, Instituto Superior Técnico, Technical University of Lisbon, Portugal. (In Portuguese).

Chai, C.; de Brito, J.; Gaspar, P. L.; Silva, A. 2014. Predicting the service life of exterior wall painting: techno-economic analysis of alternative maintenance strategies, Journal of Construction Engineering and Management 140(3): 04013057. http://dx.doi. org/10.1061/(ASCE)CO.1943-7862.0000812

Choi, H. H.; Seo, J. 2009. Safety assessment using imprecise reliability for corrosion-damaged structures, Computer-Aided Civil and Infrastructure Engineering 24(4): 293-301. http://dx.doi.org/10.1111/j.1467. 8667.2009.00597.x

Chou, J.-S.; Tsai, C. -F. 2003. Concrete compressive strenght analysis using combined classification and regression technique, Automation in Construction 12(6): 725-735.

Daniotti, B. 2003. Durability evaluation and control to prevent building pathologies, in $2^{\text {nd }}$ International Symposium on Pathology, Durability and Rehabilitation of Buildings - Learning from Construction Errors and Defects, 2003, LNEC, Lisbon, 97-105.

Daniotti, B.; Spagnolo, S. L. 2007. Service life prediction for buildings' design to plan a sustainable building maintenance, SB07 Lisbon - Sustainable Construction, Materials and Practices: Challenge of the Industry for the New Millennium, Instituto Superior Técnico, Lisbon, Portugal.

Dias, J. L.; Silva, A.; Chai, C.; Gaspar, P. L.; de Brito, J. 2013. Neural networks applied to service life prediction of exterior painted surfaces, Building Research and Information 42(3): 371-380. https://dx.doi.org/1 0.1080/09613218.2013.819551

Durbin, J.; Watson, G. S. 1971. Testing for serial correlations in least squares regression III, Biometrika 58(1): 1-19. http://dx.doi.org/10.2307/2334313

Flores-Colen, I.; de Brito, J. 2010. Discussion of proactive maintenance strategies in façades' coatings of social housing, Journal of Building Appraisal 5(3): 223-240. http://dx.doi.org/10.1057/jba.2009.21

Flourentzou, F.; Brandt, E.; Wetzel, C. 1999. MEDIC - a method for predicting residual service life and refurbishment investment budgets, in $8^{\text {th }}$ International Conference on the Durability of Building Materials and Components (DBMC), Ottawa, Canada, 1280-1288.

Garrido, M. A.; Paulo, P. V.; Branco, F. A. 2012. Service life prediction of façade paint coatings in old buildings, Construction and Building Materials 29: 394-402. http://dx.doi.org/10.1016/j.conbuildmat.2011.10.057

Gaspar, P.; de Brito, J. 2005. Assessment of the overall degradation level of an element, based on a field data, in $10^{\text {th }}$ International Conference on Durability of Buildings Materials and Components (DBMC), Lyon, France, 1043-1050.

Gaspar, P.; de Brito, J. 2008. Service life estimation of cement-rendered facades, Building Research and Information 36(1): 44-55. http://dx.doi. org/10.1080/09613210701434164

Gaspar, P. 2009. Service life of constructions: development of a method to estimate the durability of construction elements. Application to renderings of current buildings, Doctor Thesis in Sciences of Engineering. Instituto Superior Técnico, Technical University of Lisbon, Portugal. (In Portuguese).

Gaspar, P. L.; de Brito, J. 2011. Limit states and service life of cement renders on façades, Journal of Materials in Civil Engineering 23(10): 1393-1404. http:// dx.doi.org/10.1061/(ASCE)MT.1943-5533.0000312

Hair, J. F.; Black, W. C.; Babin, B.; Anderson, R. E.; Tatham, R. L. 2007. Multivariate data analysis. $6^{\text {th }} \mathrm{ed}$. Englewood Cliffs, New Jersey, USA: Prentice-Hall Publishers

Honjyo, K.; Yonemitsu, K.; Tsunenari, S. 2005. Estimation of early postmortem intervals by a multiple regression analysis using rectal temperature and nontemperature based postmortem changes, Journal of Clinical Forensic Medicine 12: 249-253. http://dx.doi. org/10.1016/j.jcfm.2005.02.003

International Standardisation Organisation (ISO) ISO 15686-1:2000 Building and constructed assets: Service life planning - Part 1: General principles. International Standard Organization, Geneva.

Iselin, D. G.; Lemer, A. C. 1993. The fourth dimension in building: strategies for minimizing obsolescence. Committee on Facility Design to Minimize Premature Obsolescence, National Academy Press, Washington DC.

Jiang, X.; Adeli, H. 2005. Dynamic wavelet neural network for nonlinear identification of high-rise buildings, Computer-Aided Civil and Infrastructure Engineering 20: 316-330. http://dx.doi.org/10.1111/j.14678667.2005.00399.x

Jiang, X.; Mahadevan, S.; Adeli, H. 2007. Bayesian wavelet packet denoising for structural system identification, Structural Control and Health Monitoring 14: 333-356. http://dx.doi.org/10.1002/stc.161

Lacasse, M. A.; Sjöström, C. 2004. Recent advances in methods for service life prediction of buildings materials and components - an overview, in CIB World Building Congress, 2004, Canada, 1-10.

Leung, A. W. T.; Tam, C. M.; Liu, D. K. 2001. Comparative study of artificial neural networks and multiple regression analysis for predicting hoisting times of tower cranes, Building and Environment 36(4): 457467. http://dx.doi.org/10.1016/S0360-1323(00)00029-9

Li, C. Q.; Lawanwisut, W.; Mackie, R. I. 2007. A risk cost optimized maintenance strategy for corrosion affected concrete structures, Computer-Aided Civil and Infrastructure Engineering 22(5): 335-346. http:// dx.doi.org/10.1111/j.1467-8667.2007.00490.x

Long, A. E.; Henderson, G. D.; Montgomery, F. R. 2001. Why assess the properties of near-surface concrete?, Construction and Building Materials 15(2-3): 65-79. http://dx.doi.org/10.1016/S0950-0618(00)00056-8 
Lounis, Z.; Vanier, D. J.; Lacasse, M. A. 1998. A discrete stochastic model for performance prediction of roofing systems, in CIB World Building Congress, Gävle, Sweden, 305-313.

Martin, J. W.; Saunders, S. C.; Floyd, F. L.; Wineburg, J. P. 1996. Methodologies for predicting the service lives of coating systems. Federation of Societies for Coatings Technology, Blue Bell, Pennsylvania, USA.

Masters, L. W.; Brandt, E. 1987. Prediction of service life of building materials and components. RILEM Technical Committee, CIB W80/RILEM 71-PSL Final Report, Materials and Structures 20: 55-77. http://dx.doi.org/10.1007/BF02472728

Mata, J. 2011. Interpretation of concrete dam behaviour with artificial neural network and multiple linear regression models, Engineering Structures 33: 903910. http://dx.doi.org/10.1016/j.engstruct.2010.12.011

Meeker, W. Q.; Escobar, L. A. 1998. Statistical methods for reliability data. New York: John Wiley \& Sons.

Möller, B.; Graf, W.; Nguyen, S. H. 2004. Modeling the life cycle of a structure using fuzzy processes, Computer-Aided Civil and Infrastructure Engineering 19(3): 157-169. http://dx.doi.org/10.1111/j.14678667.2004.00345.x

Moser, K. 2004. Engineering design methods for service life prediction. CIB W080 / RILEM 175 SLM: Service Life Methodologies Prediction of service life for Buildings and Components, Task Group: Performance based methods of service life prediction, Trondheim, Norway, 52-95.

National Statistics Institute (INE). National statistics census 2001. Available at: http://www.ine.pt/prodserv/quadro/mostraquadro.asp (In Portuguese).

Oral, M.; Oral, E. L.; Aydin, A. 2012. Supervised vs. unsupervised learning for construction crew productivity prediction, Automation in Construction 22: 271276. http://dx.doi.org/10.1016/j.autcon.2011.09.002

Park, H. S.; Lee, H. M.; Adeli, H.; Lee, I. 2007. A new approach for health monitoring of structures: terrestrial laser scanning, Computer-Aided Civil and Infrastructure Engineering 22: 19-30. http://dx.doi. org/10.1111/j.1467-8667.2006.00466.x

Rodrigues, M. F.; Teixeira, J.; Cardoso, J.; Anjos, A. 2013. Envelope index evaluation model of existing buildings, Civil Engineering and Environmental Systems 30(1): 26-39. http://dx.doi.org/10.1080/10286608.2012.709505

Savin, N. E.; White, M. B. 1977. The Durbin-Watson test for serial correlation with extreme sample sizes or array regressors, Econometrica 15: 1989-1996. http://dx.doi.org/10.2307/1914122

Shohet, I. M.; Puterman, M.; Bilboa, E. 2002. Deterioration patterns of building cladding components for maintenance management, Construction Management and Economics 20(4): 305-314. http://dx.doi. org/10.1080/01446190210125563

Shohet, I.; Paciuk, M.; Puterman, M. 2003. Deterioration patterns of exterior cladding components, in $C I B / W 87-2^{\text {nd }}$ International Symposium in Lisbon, LNEC, Lisbon, Portugal, 151-160.

Shohet, I.; Paciuk, M. 2004. Service life prediction of exterior cladding components under standard conditions, Con- struction Management and Economics 22(10): 10811090. http://dx.doi.org/10.1080/0144619042000213274

Shohet, I.; Paciuk, M. 2006. Service life prediction of exterior cladding components under failure conditions, Construction Management and Economics 24(2): 131148. http://dx.doi.org/10.1080/01446190500184535

Silva, A.; de Brito, J.; Gaspar, P. 2011a. Service life prediction model applied to natural stone wall claddings (directly adhered to the substrate), Construction and Building Materials 25(9): 3674-3684. http://dx.doi. org/10.1016/j.conbuildmat.2011.03.064

Silva, A.; Dias, J. L. R.; Gaspar, P. L.; de Brito, J. 2011 b. Service life prediction models for exterior stone cladding, Building Research and Information 39(6): 637653. http://dx.doi.org/10.1080/09613218.2011.617095

Silva, A.; de Brito, J.; Gaspar, P. 2012. Application of the factor method to maintenance decision support for stone cladding, Automation in Construction 22: 165174. http://dx.doi.org/10.1016/j.autcon.2011.06.014

Silva, A.; Dias, J. L.; Gaspar, P.; de Brito, J. 2013. Statistical model applied to service life prediction of rendered façades, Automation in Construction 30: 151160. http://dx.doi.org/10.1016/j.autcon.2012.11.028

Teo, E.; Chew, M.; Harikrishna, N. 2005. An assessment of factors affecting the service life of external paint finish on plastered facades, in $10^{\text {th }}$ International Conference on Durability of Buildings Materials and Components (DBMC), Lyon, France, 570-582.

Tolman, F.; Tolman, A. 2003. Economical and environmental sustainability in construction and operation, in $2^{\text {nd }}$ International Symposium - Integrated Lifetime Engineering of Buildings and Civil Infrastructures, Kuopio, Finland.

Wang, Y.-M.; Elhag, T. M. S. 2007. A comparison of neural network, evidential reasoning and multiple regression analysis in modelling bridge risks, Expert Systems with Applications 32: 336-348. http://dx.doi. org/10.1016/j.eswa.2005.11.029

Wang, Y.-R.; Gibson Jr., G. E. 2010. A study of reproject planning and project sucess using ANNs and regression models, Automation in Construction 19(3): 341346. http://dx.doi.org/10.1016/j.autcon.2009.12.007

Woodward, D. 1997. Life cycle costing--theory, information acquisition and application, International Journal of Project Management 15: 335-344. http://dx.doi. org/10.1016/S0263-7863(96)00089-0

Woods, V. B.; Moloney, A. P.; Calsamiglia, S.; O'Mara, F.P. 2003. The nutritive value of concentrate feedstuffs for ruminant animals: Part III. Small intestinal digestibility as measured by in vitro or mobile bag techniques, Animal Feed Science and Technology 110: 145-157. http://dx.doi.org/10.1016/ S0377-8401(03)00221-9

Zhang, Y.; Vidakovic, B.; Augenbroe, G. 2005. Uncertainty analysis in using Markov chain model to predict roof life cycle performance, in $10^{\text {th }}$ International Conference on the Durability of Building Materials and Components (DBMC), Lyon, France, 96-121.

Zhang, X.; Gao, H. 2012. Determining an optimal maintenance period for infrastructure systems, Computer-Aided Civil and Infrastructure Engineering 27(7): 543-554. http://dx.doi.org/10.1111/j.14678667.2011.00739.x 